\title{
Parâmetros da incubação e componentes dos ovos de codornas japonesas para corte (Coturnix japonica) submetidos à estocagem em baixas temperaturas $\left(7,5 \pm 1^{\circ} \mathrm{C}\right)$
}

\section{Incubation parameters and compounds of meat type japanese quail (Coturnix japonica) eggs stored at low temperatures $\left(7.5 \pm 1^{\circ} \mathrm{C}\right.$ )}

\author{
Thania Gislaine Vasconcelos de Moraes ${ }^{1}$; Josue Moura Romao²; \\ William Maciel Cardoso ${ }^{3 *}$
}

\begin{abstract}
Resumo
O objetivo deste trabalho foi avaliar os efeitos da estocagem em baixa temperatura $\left(7,5 \pm 1^{\circ} \mathrm{C}\right)$ sobre os parâmetros de incubação e proporção dos componentes de ovos de codornas japonesas para corte. Foram realizadas coletas de ovos de codornas japonesas (Coturnix japonica) durante 22 dias consecutivos, obtendo-se um total de 440 ovos. Estes foram identificados individualmente e pesados. Os ovos foram submetidos a diferentes períodos de estocagem, variando de zero até vinte dias. Os ovos foram estocados em um refrigerador doméstico $\left(7,5 \pm 1{ }^{\circ} \mathrm{C}\right.$ e $50 \%$ umidade relativa) após a coleta diária. Após a estocagem, os ovos foram incubados a $37,5^{\circ} \mathrm{C}$ com $60 \%$ UR e viragem automática a cada meia hora. Os pintinhos nascidos foram pesados individualmente. Os resultados demonstraram que a eclodibilidade foi satisfatória em todos os grupos, sendo a eclodibilidade mais baixa nos ovos estocados por 20 dias $(60 \%)$. A perda de peso dos ovos aumentou de acordo com o aumento dos dias de estocagem com valor máximo de $3,4 \%$ nos ovos do $20^{\circ}$ dia. Não foi encontrada relação entre o tempo de estocagem e a perda de peso na incubação.
\end{abstract}

Palavras-chave: Eclodibilidade, coturnicultura, peso ao nascer

\begin{abstract}
The objective of this research was to evaluate the effects of egg storage at low temperatures $\left(7.5 \pm 1{ }^{\circ} \mathrm{C}\right)$ on incubation parameters and egg compounds of meat type Japanese quail eggs. The egg sampling of meat type Japanese quail (Coturnix japonica) was done during 22 consecutive days, totaling 440 eggs. They were individually identified and weighted. They were stored in a domestic refrigerator $(7.5 \pm 1$ ${ }^{\circ} \mathrm{C}$ and $50 \%$ relative humidity). After storage, they were incubated at $37.5^{\circ} \mathrm{C}$ with $60 \% \mathrm{RH}$ and turning every 30 minutes. Hatched chicks were weighted individually. The results showed that the hatchability was satisfactory in all groups. The lowest hatchability was in the eggs stored for 20 days (60\%). Egg weight loss during storage reached $3.4 \%$ at $20^{\text {th }}$ day. There was no relation between storage period and egg weight loss during incubation.
\end{abstract}

Key words: Hatchability, quail raising, hatch weight

${ }^{1}$ Bolsista do Laboratório de Estudos Ornitológicos - UECE. thaniagislaine@yahoo.com.br

2 Bolsista do Laboratório de Estudos Ornitológicos - UECE. josueromao@yahoo.com.br

3 Professor da Faculdade de Veterinária - UECE. william.maciel@uol.com.br Endereço postal: Rua 60, Casa 541, Terceira Etapa Bairro: José Walter, CEP: 60750-740, Fortaleza, Ceará, Brasil.

* Autor para correspondência 


\section{Introdução}

A codorna japonesa, tradicionalmente criada para produção de ovos comerciais, também vem sendo produzida para corte (BAUMGARTNER, 1994; MINVIELLE, 1998). Nos últimos 40 anos, os geneticistas avícolas vêm trabalhando no sentido de obter aves mais precoces, mais pesadas e muito mais produtivas em linhagens de corte (CAMPOS; SANTOS, 2003). No Brasil, a linhagem de codorna japonesa para corte é conhecida popularmente como codorna italiana (MÓRI et al., 2005).

A incubação é essencial para a manutenção e o aperfeiçoamento da criação de codornas, que tem se difundido bastante pelo Brasil nos últimos anos. A estocagem de ovos é uma prática comum nos processos de incubação. Ela tem o objetivo de reduzir os custos com transporte dos ovos para o incubatório, obter número de ovos suficientes para preencher as máquinas incubadoras e sincronizar os nascimentos (FASENKO et al., 2001a), sendo também fundamental para o planejamento da produção das aves. $\mathrm{O}$ armazenamento de ovos para posterior incubação deve ser feito em ambientes com temperaturas inferiores ao zero fisiológico $\left(20^{\circ} \mathrm{C}\right)$ para assegurar a parada completa do desenvolvimento embrionário e evitar um possível desenvolvimento desproporcional do embrião em temperaturas entre o zero fisiológico e a temperatura ideal de incubação (GONZÁLES; CESARIO, 2003).

Diversos autores relatam que ovos estocados por mais de duas semanas devem ser mantidos em baixas temperaturas $\left(10\right.$ a $\left.12{ }^{\circ} \mathrm{C}\right)$ (BUTLER, 1991; MEIJERHOF, 1992; WILSON, 1991). A temperatura de estocagem influencia na qualidade do albúmen (WALSH, 1993), na perda de água pelo ovo (SCOTT; SILVERSIDES, 2000) e na eclodibilidade (REIS; GAMA; CHAVEIRO SOARES, 1997). Apesar da perda de água do ovo para o ambiente ser um processo natural que ocorre por difusão através da casca (NORTH, 1984), a redução da qualidade interna dos ovos está associada principalmente à perda de água e de dióxido de carbono durante o período de estocagem, e é proporcional à elevação da temperatura do ambiente (AUSTIC; NESHEIM, 1990; CRUZ; MOTA, 1996).

Segundo Narahari et al. (1988) e Peebles e Marks (1991), a qualidade interna e externa dos ovos influencia a eclodibilidade e o desenvolvimento do pintinho de codorna. A avaliação da qualidade do ovo é feita principalmente pelas características do albúmen (SILVERSIDES; SCOTT, 2001), mas também pela proporção dos componentes do ovo (AHN; KIM; SHU, 1997).

O objetivo deste trabalho foi avaliar os efeitos da estocagem em baixas temperaturas $\left(7,5 \pm 1{ }^{\circ} \mathrm{C}\right)$ sobre a eclodibilidade, perda de peso dos ovos, peso ao nascer e a proporção dos componentes de ovos de codornas japonesas para corte.

\section{Material e Métodos}

Foram utilizadas 45 codornas japonesas de corte (Coturnix japonica) para coletas diárias de ovos. As aves foram alojadas na proporção de um macho para duas fêmeas em gaiolas experimentais do Setor de Estudos Ornitológicos da Universidade Estadual do Ceará. As aves tinham 12 semanas de idade e uma média de $90 \%$ de produção. As codornas receberam ração balanceada, água ad libitum e foram submetidas a um programa de iluminação de 17 horas/dia.

As coletas foram realizadas diariamente às sete horas. Os ovos foram selecionados de acordo com os parâmetros industriais de incubação, verificando o formato do ovo, tamanhos extremos (inferiores a $11 \mathrm{~g}$ ou superiores a $15 \mathrm{~g}$ ) e integridade da casca através da ovoscopia. Durante 22 dias consecutivos, 20 ovos foram selecionados por dia, totalizando 440 ovos. Eles foram estocados em um refrigerador doméstico $\left(7,5 \pm 1{ }^{\circ} \mathrm{C}\right.$ e $50 \%$ de umidade relativa) logo após a coleta. Os ovos foram submetidos a diferentes períodos de estocagem, variando de zero até 20 dias. Os ovos dos dias de coleta 1, 3, 5, 7, 
9, 11, 13, 15, 17, 19 e 21 foram incubados após a estocagem, enquanto os ovos dos demais dias de coleta foram utilizados para avaliar os efeitos da estocagem nas características dos ovos.

Todos os ovos foram identificados individualmente e pesados com balança de precisão $(0,001 \mathrm{~g})$. Os ovos submetidos somente à estocagem foram pesados no dia da coleta e no fim do período de armazenagem. Os submetidos à estocagem e incubação foram pesados no dia da coleta, no fim do período de estocagem e no décimo quinto dia de incubação para verificar a perda de peso do ovo. Todos os pintinhos foram pesados após o nascimento.

Os ovos foram incubados na posição horizontal em incubadoras automáticas com temperatura de $37,5{ }^{\circ} \mathrm{C}$, umidade relativa controlada de $60 \%$ e viragem automática a cada 30 minutos. No décimo quinto dia de incubação os ovos foram transferidos para a nascedoura, onde foram mantidas a mesma temperatura e umidade, porém, sem a viragem dos ovos. O nascimento foi realizado até no máximo 21 dias de incubação, posteriormente foi feito o cálculo da eclodibilidade a seguir: $\mathrm{n}^{\mathrm{o}}$ de ovos eclodidos/ $n^{\circ}$ de ovos total $x 100$. O cálculo de perda de peso dos ovos foi feito excluindo o valor dos ovos não eclodidos, pois estes alteram a média real por perderem mais peso que os ovos eclodidos (SOLIMAN; RIZK; BRAKE, 1994).

Um total de 220 ovos foi submetido apenas à estocagem. Eles foram pesados durante a estocagem e abertos para avaliar os componentes do ovo. As cascas foram separadas do restante do ovo, submetidas à secagem em estufa por $24 \mathrm{~h}$ a $60^{\circ} \mathrm{C} \mathrm{e}$ posteriormente pesadas individualmente. As gemas foram separadas e pesadas individualmente em balança de precisão. $\mathrm{O}$ peso do albúmen foi obtido pela subtração do peso da gema e casca do peso total do ovo.

Os dados foram analisados pelo programa software Statistix 1.0 (STATISTIX ..., 1996). Os resultados foram submetidos à análise de variância através do modelo geral linear (GML) e as médias foram comparadas pelo teste de Tukey com probabilidade de $\mathrm{p}<0,05$.

\section{Resultados e Discussão}

A figura 1 mostra o percentual de eclodibilidade dos ovos de codornas japonesas para corte submetidos à estocagem de 0 a 20 dias a baixa temperatura $\left(7,5 \pm 1^{\circ} \mathrm{C}\right)$.

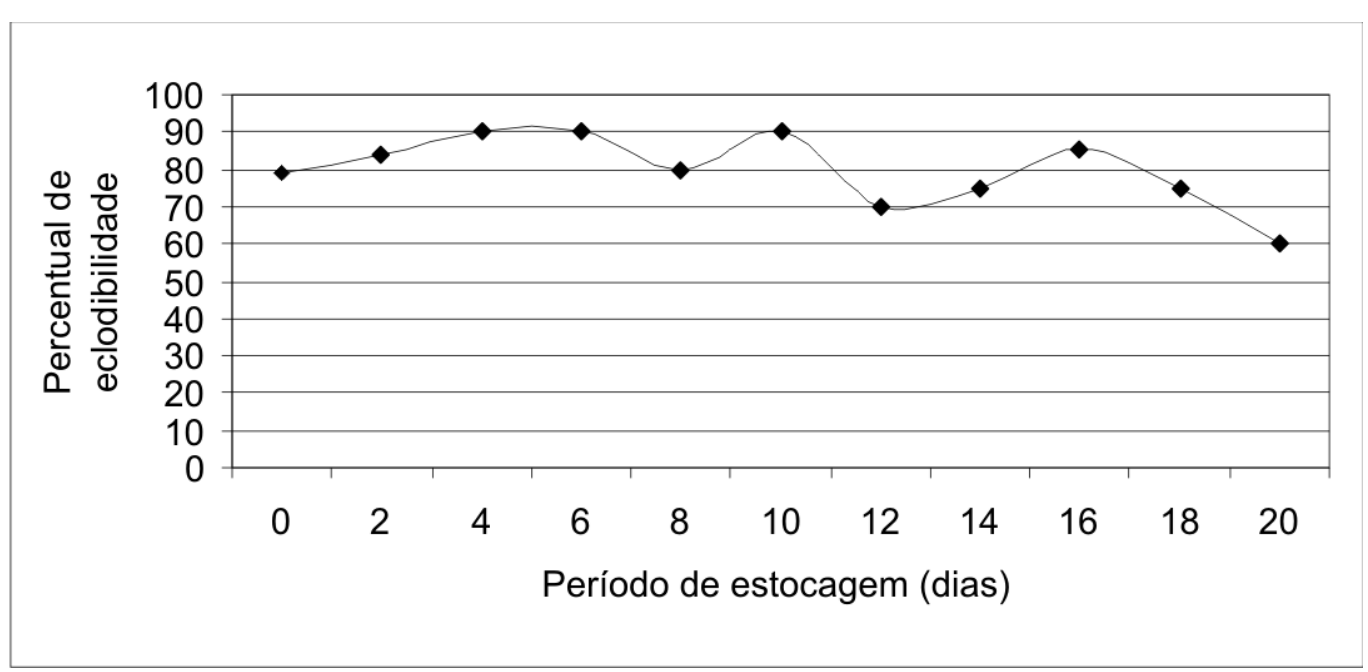

Figura 1. Eclodibilidade dos ovos de codorna japonesa para corte submetidos a diferentes períodos de estocagem à baixa temperatura $\left(7,5 \pm 1^{\circ} \mathrm{C}\right)$ 
A média de eclodibilidade de todos os grupos foi de 79,83\%. Os índices de eclodibilidade obtidos neste trabalho variaram de 60 a $90 \%$. Foi observado um declínio na eclodibilidade a partir do $16^{\circ}$ dia de estocagem até o $20^{\circ}$ dia. De acordo com Becker (1964), estocagens longas causam uma redução da eclodibilidade dos ovos. Alguns estudos relataram o declínio na eclodibilidade devido à estocagem de ovos de perus e codornas japonesas (SITTMANN; ABPLANALP; MEYERDICK, 1971), frangos de corte (KIRK et al., 1980) e avestruzes (DEEMING, 1996).

A eclodibilidade de ovos de codornas japonesas para corte foi de $90 \%$ para quatro dias de estocagem e $75 \%$ para 14 dias de estocagem. Fasenko et al. (2001a) encontraram eclodibilidade de 87,5\% e 70,5\% para ovos de galinhas estocados por 4 e 14 dias, respectivamente. Os mesmos autores encontraram, nas mesmas condições, 70,42\% e $65,6 \%$ em ovos de perus (FASENKO et al., 2001b). Contudo, as temperaturas usadas por Fasenko et al. (2001a, 2001b) durante a estocagem foram superiores a temperatura de estocagem utilizada neste experimento, sendo para ovos de galinhas e ovos de perus de $11,5^{\circ} \mathrm{C}$ e $17,4^{\circ} \mathrm{C}$, respectivamente.
Seker, Kul e Bayraktar (2005) armazenaram ovos de codornas japonesas a temperaturas que variaram de 9 a $12{ }^{\circ} \mathrm{C}$ com 70 a $75 \%$ UR por 15 dias e encontraram os seguintes percentuais de eclodibilidade: $90 \%$ para os ovos estocados até três dias, $88,74 \%$ para os ovos estocados de quatro a seis dias, $67,96 \%$ para os ovos estocados de sete a nove dias, $72,45 \%$ para os ovos estocados de 10 a 12 dias e 50,31\% para os estocados de 13 a 15 dias. Sittmann, Abplanalp e Meyerdick (1971) observaram a eclodibilidade de ovos de codornas japonesas estocados entre 4 e 38 dias a temperatura de $13,3{ }^{\circ} \mathrm{C}$ e encontraram $78,6 \%$ de eclodibilidade dos ovos estocados por 4 dias, $76,9 \%$ por 8 dias, $72,4 \%$ por 13 dias, $59,7 \%$ por 18 dias, $47,5 \%$ por 23 dias e $8,8 \%$ por 38 dias de estocagem.

Comparando com os trabalhos de Seker, Kul e Bayraktar (2005) e Sittmann, Abplanalp e Meyerdick (1971) neste trabalho foi observado melhores índices de eclodibilidade em ovos estocados até 20 dias, podendo ter sido devido a baixa temperatura de estocagem $\left(7,5 \pm 1^{\circ} \mathrm{C}\right)$.

A figura 2 mostra a perda de peso dos ovos de codornas japonesas (eclodidos) submetidos a diferentes períodos de estocagens à temperatura de $7,5 \pm 1{ }^{\circ} \mathrm{C}$.

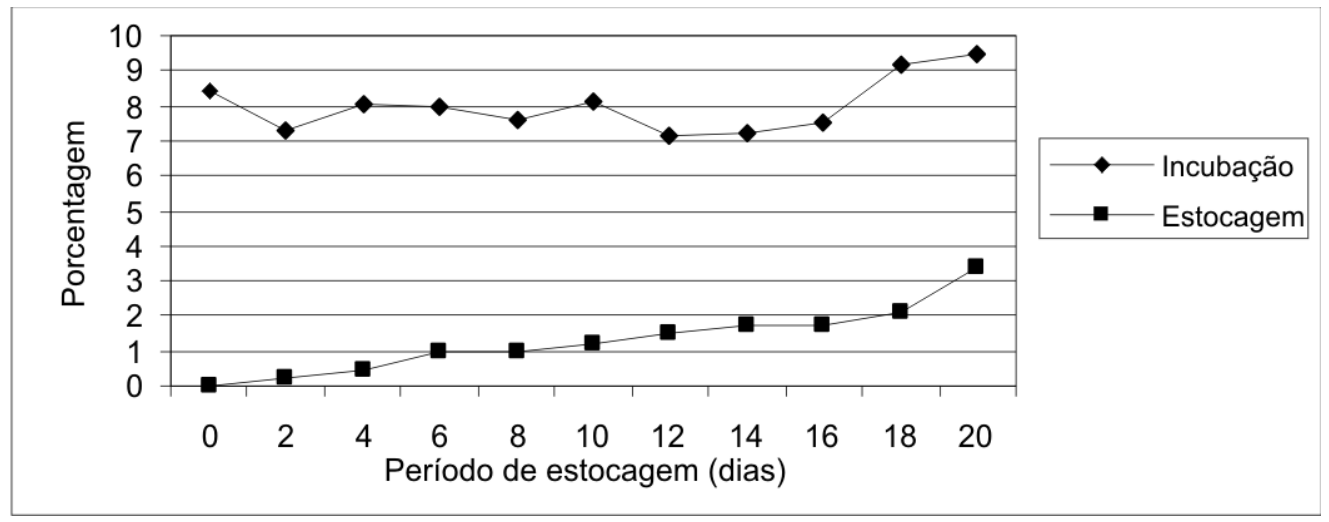

Figura 2. Perda de peso dos ovos de codornas japonesas para corte submetidos à estocagem a baixa temperatura $\left(7,5 \pm 1^{\circ} \mathrm{C}\right)$ 
A perda de peso dos ovos durante a estocagem cresceu ao longo dos dias, atingindo $3,40 \%$ de perda de peso no grupo estocado por 20 dias. Apesar do aumento da perda de peso dos ovos ao longo da estocagem, as médias de peso dos ovos dos diferentes grupos não apresentaram diferença entre os diferentes dias $(\mathrm{p}<0,05)$.

Samli, Agma e Senkoylu (2005) estocaram ovos de galinha a $5{ }^{\circ} \mathrm{C}$ e $60 \%$ UR por 2,5 e 10 dias e observaram $0,27 \% ; 0,51 \%$ e $0,66 \%$ de perda de peso dos ovos durante a estocagem, respectivamente. Neste experimento foram observados os valores de $0,37 \%$; $0,96 \%$ e $1,67 \%$ para 2,6 e 10 dias de estocagem, respectivamente. Estas perdas de peso foram superiores devido a uma maior temperatura e uma menor umidade relativa na estocagem.

A perda de peso do ovo é um importante parâmetro da incubação, pois é usada para estimar as trocas de gases do embrião (PAGANELLI; ACKERMAN; RAHN, 1978; RAHN; AR;
PAGANELLI, 1979) e está correlacionada ao metabolismo embrionário e ao seu desenvolvimento (RAHN; AR, 1980). Soliman, Rizk e Brake (1994) observaram que ovos de codornas japonesas que eclodiram perderam $11,3 \%$ do seu peso inicial do $1^{\circ}$ ao $15^{\circ}$ dia de incubação. A perda de peso durante a incubação de codornas japonesas de corte estocadas em baixas temperaturas teve média de $8 \%$, apresentando variações entre $7,11 \%$ e $8,41 \%$, neste trabalho. Apesar da variação entre os grupos, esta não foi estatisticamente significativa. Os ovos deste experimento apresentaram menor perda de peso quando comparado aos do experimento de Soliman, Rizk e Brake, (1994), provavelmente pelo uso de uma diferente umidade na incubação (aproximadamente 60\% UR). Não foi verificada correlação entre o período de estocagem e a perda de peso do ovo durante a incubação.

Figura 3 mostra a relação percentual entre o peso do pintinho ao nascer e o peso dos ovos de codornas japonesas de corte estocados a baixa temperatura.

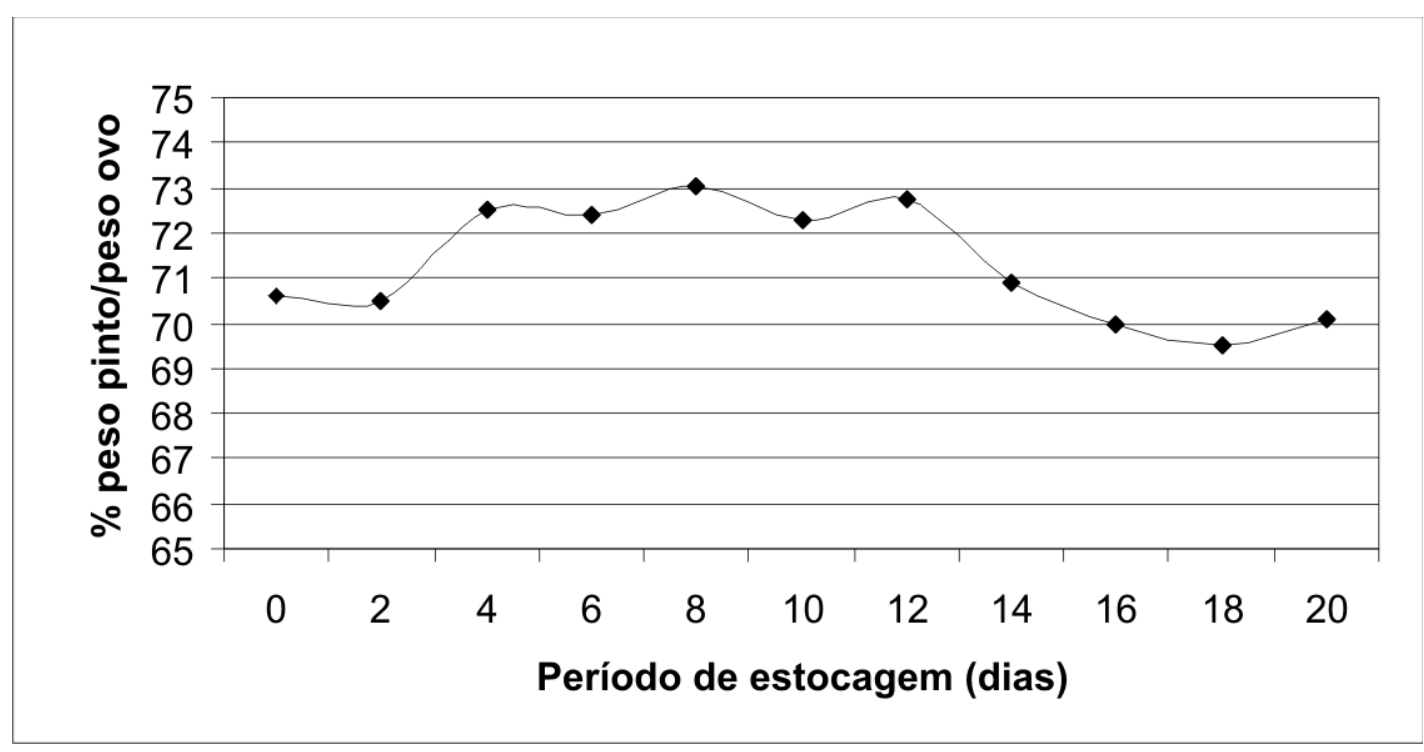

Figura 3. Relação percentual do peso do pintinho/peso do ovo de codornas japonesas para corte estocados a $7,5 \pm 1^{\circ} \mathrm{C}$ 
Ao nascimento todos os pintinhos foram pesados para a determinação da relação percentual entre o peso do pintinho e o do ovo, e este variou entre 70 e $71 \%$ nos ovos não estocados e estocados por dois dias; já os ovos estocados entre 4 e 12 dias obtiveram a relação entre 72 e $73 \%$ e os ovos estocados de 14 a 20 dias obtiveram as menores relações, variando entre 69 e $71 \%$.

Não foi encontrada correlação entre o período de estocagem e o peso corporal dos pintinhos ao nascer, entretanto houve diferença $(\mathrm{p}<0,05)$ de peso entre os pintinhos nascidos de ovos estocados por 8 dias e pintinhos nascidos de ovos estocados por 18 dias, obtendo-se, respectivamente, as seguintes relações entre o peso do pintinho e o do ovo de $73,03 \%$ e $69,49 \%$, resultados semelhantes foram obtidos por Sachdev et al. (1988) que observaram que o peso ao nascer dos pintinhos de codornas eclodidos de ovos estocados por curtos períodos são superiores ao de ovos estocados por longos períodos. Entretanto, Petek et al. (2005) não encontraram interferência significativa entre o peso ao nascer de codornas e o número de dias que estes foram estocados antes da incubação.

Além do período de estocagem dos ovos, outros fatores podem influenciar o peso do pintinho ao nascer, como a idade das aves reprodutoras e o tempo de incubação (CRITTENDEN; BOHREN, 1961; SMITH; BOHREN, 1975). Porém outros autores afirmam que o peso do ovo é o fator dominante na determinação do peso ao nascer (SILVERSIDES; SCOTT, 2001; TONA et al., 2002).

Tabela 1 mostra o efeito da estocagem em baixas temperaturas sobre os componentes dos ovos de codornas japonesas para corte.

Tabela 1. Efeito da estocagem a baixa temperatura $\left(7,5 \pm 1^{\circ} \mathrm{C}\right)$ nos componentes dos ovos de codornas japonesas para corte.

\begin{tabular}{llll}
\hline Tempo de Estocagem & Albúmen $(\%) \pm$ DP & Casca $(\%) \pm$ DP & Gema (\%) \pm DP \\
\hline 0d & $62,85 \pm 1,99$ & $7,96 \pm 0,17$ & $29,19 \pm 2,00$ \\
2d & $63,52 \pm 1,13$ & $8,06 \pm 0,42$ & $28,42 \pm 1,10$ \\
$4 \mathrm{~d}$ & $63,31 \pm 1,39$ & $7,98 \pm 0,49$ & $28,71 \pm 1,44$ \\
$6 \mathrm{~d}$ & $62,11 \pm 2,16$ & $7,75 \pm 0,86$ & $30,14 \pm 1,82$ \\
$8 \mathrm{~d}$ & $62,13 \pm 1,79$ & $8,16 \pm 0,64$ & $29,71 \pm 1,61$ \\
$10 \mathrm{~d}$ & $62,50 \pm 1,70$ & $7,91 \pm 0,51$ & $29,59 \pm 1,72$ \\
$12 \mathrm{~d}$ & $62,23 \pm 1,73$ & $8,10 \pm 0,65$ & $29,67 \pm 1,67$ \\
$14 \mathrm{~d}$ & $61,13 \pm 2,13$ & $8,35 \pm 0,27$ & $30,52 \pm 2,47$ \\
$16 \mathrm{~d}$ & $60,22 \pm 1,64$ & $8,47 \pm 0,40$ & $31,31 \pm 1,57$ \\
$18 \mathrm{~d}$ & $61,72 \pm 1,72$ & $8,05 \pm 0,56$ & $30,23 \pm 1,56$ \\
$20 \mathrm{~d}$ & $60,30 \pm 2,54$ & $8,52 \pm 0,52$ & $31,18 \pm 2,41$ \\
\hline
\end{tabular}

O tempo de estocagem e a temperatura são fatores cruciais que afetam a qualidade do albúmen (SAMLI; AGMA; SENKOYLU, 2005). De acordo com muitos estudos, a unidade Haugh, os pesos do ovo, do albúmen, da gema, da casca e a espessura da casca são afetados pelo tempo de estocagem (ALTAN et al., 1997; SUK; PARK, 2001; TILKI; INAL, 2004).
Nos ovos de codornas japonesas de corte estocados a baixa temperatura não foi observada diferença estatística significativa no percentual do albúmen. Segundo Samli, Agma e Senkoylu (2005), a perda de água pelo ovo em baixas temperaturas $\left(5^{\circ} \mathrm{C}\right)$ não se altera significativamente com o aumento do período de estocagem, não afetando consideravelmente os componentes do 
ovo. Entretanto Tilki e Saatci (2004) ao estudar os efeitos da estocagem nos componentes dos ovos de perdizes, observou uma redução do percentual do albúmen ao longo da estocagem. A redução do albúmen ao longo da estocagem está associada à perda de água do ovo para o ambiente devido à evaporação (ROMANOFF; ROMANOFF, 1949).

Não foi encontrada influência do período de estocagem sobre o peso da gema, o que está de acordo com os resultados de Fasenko et al. (2001a). Silversides e Villeneuve (1994) estudaram o efeito da estocagem sobre ovos de galinha e observaram que a estocagem reduz o percentual do albúmen devido à transferência de água do albúmen para o meio e para gema, aumentando o percentual da mesma.

Foi verificado um aumento do percentual da casca em relação ao peso total do ovo, contudo, não houve diferença estatística entre os valores. Segundo Silversides e Villeneuve (1994), o aumento do percentual da casca ao longo dos dias de estocagem é devido apenas à redução do peso do ovo, pois o peso absoluto da casca não se altera durante a estocagem.

\section{Conclusões}

Pode-se concluir que a estocagem de ovos de codornas para corte a baixa temperatura não prejudicou consideravelmente a eclodibilidade mesmo em ovos estocados por longos períodos. Não foi verificada correlação entre o período de estocagem e a perda de peso do ovo durante a incubação. Não foi encontrada uma correlação entre o período de estocagem e o peso corporal dos pintinhos ao nascer. Não foi observada diferença estatística no percentual do albúmen ao longo da estocagem.

\section{Referências}

AHN, D. U.; KIM, S. K.; SHU, H. Effect of egg size and strain and age of hen on the solids content of chicken eggs. Poultry Science, Champaign, v. 76, n. 6, p. 914 919, 1997.

ALTAN, O.; AKBAS, Y.; SEVGICAN, F.; ERKEK, R. Effects of cold storage on egg quality. Turkish Journal of Veterinary and Animal Science, Ankara, v. 21, n. 4, p. 335-339, 1997.

AUSTIC, R. E.; NESHEIM, M. C. Poultry production. 13. ed. London: Lea Febiger, 1990.

BAUMGARTNER, J. Japanese quail production, breeding and genetics. World's Poultry Science Journal, Ithaca, v. 50, n. 3, p. 227-235, 1994.

BECKER, W. A. The storage of white leghorn chicken eggs in plastic bags. Poultry Science, Champaign, v. 43, n.5, p. 1109-1112, 1964.

BUTLER, D. E. Egg handling at the farm and hatchery. Poultry Science Symposium Series, v. 22, Carfax Publishing Oxfordshire, UK, p. 195-203, 1991.

CAMPOS, E. J.; SANTOS, J. E. C. Efeito de linhagens sobre o desenvolvimento embrionário. In: MACARI, M.; GONZÁLES. E. Manejo da incubação. Campinas: FACTA, 2003. p. 353-360.

CRITTENDEN, L. B.; BOHREN, B. B. The genetic and environmental effect of hatching time, egg weight, and holding time on hatchability. Poultry Science, Champaign, v. 40, n.6, p. 1736-1750, 1961.

CRUZ, F. G. G.; MOTA, M. O. S. Efeito da temperatura e do período de armazenamento sobre a qualidade interna dos ovos comerciais em clima tropical úmido. In: CONFERÊNCIA APINCO'96 DE CIÊNCIA E TECNOLOGIA AVÍCOLAS, 1996, Campinas. Anais... Campinas: FACTA, 1996. p. 96.

DEEMING, D. C. Production, fertility and hatchability of ostrich (Struthio camelus) eggs on a farm in the United Kingdom. Animal Science, Penicuik, v. 63, n.2, p. 329336, 1996.

FASENKO, G. M.; ROBINSON, F. E.; WHELAN, A. I.; KREMENIUK, K. M.; WALKER, J. A. Prestorage incubation of long-term stored broiler breeder eggs: 1. Effects on hatchability. Poultry Science, Champaign, v. 80 , n. 10, p. 1406-1411, 2001a.

FASENKO, G. M.; CHRISTENSEN, V. L.; WINELAND, M. J.; PETITTE, J. N. Examining the effects of prestorage incubation on turkey breeder eggs on embryonic development and hatchability of eggs stored for four or fourteen days. Poultry Science, Champaign, v. 80, n. 2, p. 132-138, 2001b. 
GONZÁLES, E.; CESARIO, M. D. Desenvolvimento embrionário. In: MACARI, M.; GONZÁLES, E. Manejo da incubação. Campinas: FACTA, 2003. p. 51-64.

KIRK, S. S.; EMMANS, G. C.; MCDONALD, R.; ARNOT, D. Factors affecting the hatchability of eggs from broiler breeders. British Poultry Science, London, v. 21, n. 1, p. 37-53, 1980.

MEIJERHOF, R. Pre-incubation holding of hatching eggs. World's Poultry Science Journal, Ithaca, v. 48, n. 1, p. 57-68, 1992.

MINVIELLE, F. Genetic and breeding of Japanese quail for production around the world. In: ASIAN PACIFIC POULTRYCONGRESS, 6., 1998, Nagoya.Proceedings... Nagoya: Japan Poultry Science Association, 1998. p. 122-127.

MÓRI, C.; GARCIA, E. A.; PAVAN, A. C.; PICCININ, A.; SCHERER, M. R.; PIZZOLANTE, C. C. Desempenho e qualidade dos ovos de codornas de quatro grupos genéticos. Revista Brasileira de Zootecnia, Viçosa, v. 34, n. 3, p. 864-869, 2005.

NARAHARI, D.; ABDUL-MUJEV, K.; THANGAVEL, A.; RAMAMURTY, N.; VISUNATHAN, S.; MOHAN, B.; MURGANANDA, B.; SUNRARAROSU, V. Traits influencing the hatching performance of Japanese quail eggs. British Poultry Science, London, v. 29, n. 1, p. 101$112,1988$.

NORTH, M. O. Maintaining hatching egg quality. Commercial chicken production manual. 3. ed. Westport: Avi Publishing Company, 1984.

PAGANELLI, C. V.; ACKERMAN, R. A.; RAHN, H. The avian egg: In vitro condutances to oxygen, carbon dioxide, and water vapor in late development. In: PIIPER, J. Respiratory function in birds, adult and embryonic. Berlin: Springer-Verlag, 1978. p. 212-218.

PEEBLES, E. D.; MARKS, H. L. Effects of selection for growth and selection diet on egg shell quality and embryonic development in Japanese quail. Poultry Science, Champaign, v. 70, n.7, p. 1471-1480, 1991.

PETEK, M.; BASPINAR, H.; OGAN, M.; BALCI, F. Effects of egg weight and length of storage period on hatchability and subsequent laying performance of quail. Turkish Journal of Veterinary and Animal Science, Ankara, v. 29, n. 2, p. 537-542, 2005.

RAHN, H.; AR, A. Gas exchange of the avian egg: time, structure and function. American Zoologist, Thousand Oaks, v. 20, n. 2, p. 477-484, 1980.

RAHN, H.; AR, A.; PAGANELLI, C. V. How bird eggs breathe. Scientific American, New York, v. 240, n. 2, p. 46-55, 1979.
REIS, L. H.; GAMA, L. T.; CHAVEIRO SOARES, M. Effects of short storage conditions and broiler breeder age on hatchability, hatching time, and chick weights. Poultry Science, Champaign, v. 76, n. 11, p. 1459-1466, 1997.

ROMANOFF, A. L.; ROMANOFF, A. J. The avian egg. New York: John Wiley, 1949.

SACHDEV, A. K.; AHUJA, S. D.; THOMAS, P. C.; AGRAWAL, S. K. Effect of egg weight and storage periods of hatching eggs on growth of chicks in Japanese quail. Indian Journal of Poultry Science, Chandra Nagar, v. 23 , n. 1, p. 14-17, 1988.

SAMLI, H. E.; AGMA, A.; SENKOYLU, N. Effects of storage time and temperature on egg quality in old laying hens. Journal of Applied Poultry Research, Athens, v. 14, n. 3, p. 548-553, 2005.

SCOTT, T. A.; SILVERSIDES, F. G. The effect of storage and strain of hen on egg quality. Poultry Science, Champaign, v. 79, n. 12, p. 1725-1729, 2000.

SEKER, I.; KUL, S.; BAYRAKTAR, M. Effects of storage period and egg weight of Japanese quail eggs on hatching results (short communication). Archiv Für Tierzucht, Dummerstorf, v. 48, n.5, p. 518-526, 2005.

SILVERSIDES, F. G.; SCOTT, T. A. Effect of storage and layer age on quality of eggs from two lines of hens. Poultry Science, Champaign, v. 80, n. 11, p. 1240-1245, 2001.

SILVERSIDES, F. G.; VILLENEUVE, P. Is the Haugh Unit correction for egg weight valid for eggs stored at room temperature? Poultry Science, Champaign, v. 73, n.1, p. 50-55, 1994.

SITTMANN, K.; ABPLANALP, H.; MEYERDICK, C. F. Extended storage of quail, chicken, and turkey eggs.1.Hatchability and embryonic mortality. Poultry Science, Champaign, v. 50, n.3, p. 681-688, 1971.

SMITH, K. P.; BOHREN, B. B. Age of pullet effect on hatching time, egg weight, and hatchability. Poultry Science, Champaign, v. 54, n.4, p. 959-963, 1975.

SOLIMAN, F. N. K.; RIZK, R. E.; BRAKE, J. Relationship between shell porosity, shell thickness, egg weight loss, and embryonic development in Japanese quail eggs. Poultry Science, Champaign, v. 73, n.10, p. 1607-1611, 1994.

STATISTIX for Windows: user's manual. Tallahassee: Analytical Software, 1996. Version 1.0.

SUK, Y. O.; PARK, C. Effect of breed and age of hens on the yolk to albumen ratio in two different genetic stocks. Poultry Science, Champaign, v. 80, n. 7, p. 855-858, 2001. 
TILKI, M.; INAL, S. Quality traits of goose eggs. 1. Effects of goose age and storage time of eggs. Archiv Für Geflugelkunde, Berlin, v. 68, n.4, p. 182-186, 2004.

TILKI, M.; SAATCI, M. Effects of storage time on external and internal characteristics in partridge (Alectoris graeca) eggs. Revue de Medecine Veterinaire, Toulouse, v. 155, n. 11, p. 561-564, 2004.

TONA, K.; BAMELIS, F.; DE KETELAERE, B.; BRUGGEMAN, V.; DECUYPERE, E. Effect of induced molting on albumen quality, hatchability, and chick body weight from broilers breeders. Poultry Science, Champaign, v. 81, n. 3, p. 327-332, 2002.
WALSH, T. J. The effects of flock age, storage humidity, carbon dioxide, and length of storage on albumen characteristics, weight loss and embryonic development of broiler eggs. 1993. Master Thesis. (Master in Poultry Science) - North Carolina State University, Raleigh.

WILSON, H. R. Physiological requirements of the developing embryo: Temperature and turning. Poultry Science Symposium Series, v. 22, Carfax Publishing Oxfordshire, UK, p. 1445-1456, 1991. 
